\title{
Digital transformation-life cycle assessment of digital services, multifunctional devices and cloud computing
}

\author{
René Itten ${ }^{1}$ (D) Roland Hischier ${ }^{2}$ - Anders S. G. Andrae ${ }^{3}$. Jan C. T. Bieser ${ }^{4}$ - Livia Cabernard ${ }^{5}$. Annemarie Falke ${ }^{6}$.

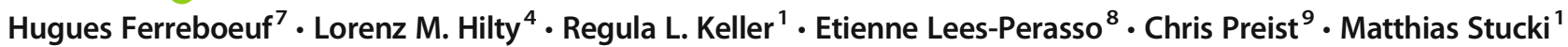

Received: 20 July 2020 / Accepted: 28 July 2020 / Published online: 12 August 2020

(C) The Author(s) 2020

\section{Introduction and overview}

The substitution of material-based services with digital services - for example films or music - alters the environmental impact of our everyday activities and shifts visible material use to less visible digital services. A holistic life cycle assessment (LCA) of digital transformation requires the assessment of information and communication technology (ICT) with its wide range of multifunctional devices as well as substitution and summation effects caused by new services enabled by modern ICT. The 73rd Discussion Forum on Life Cycle Assessment (DF LCA) was held on 21 November 2019 to discuss the environmental implications of digital transformation in view of the effective as well as the potential environmental impacts. While currently being a small but already relevant contributor to the overall greenhouse gas emissions, the relevance of the ICT sector is predicted to grow rapidly

\footnotetext{
Conference report: $73^{\mathrm{RD}}$ Discussion Forum on Life Cycle Assessment

René Itten

rene.itten@zhaw.ch

1 Institute of Natural Resource Sciences, Zurich University of Applied Sciences, Wädenswil, Switzerland

2 Technology and Society Laboratory, Empa - Swiss Federal Laboratories for Material Science and Technology, St. Gallen, Switzerland

3 R\&D Center, Huawei Technologies, Stockholm, Sweden

4 Department of Informatics, University of Zürich, Zürich, Switzerland

5 Institute of Science, Technology and Policy, Eidgenössische Technische Hochschule, Zurich, Switzerland

6 Technische Universität Bergakademie, Freiberg, Germany

7 The Shift Project, Paris, France

8 Bureau Veritas LCIE, Grenoble, France

9 Department of Computer Science, University of Bristol, Bristol, UK
}

within the next 5 to 10 years (Belkhir \& Elmeligi, 2018). This 1-day forum offered the possibility to discuss current as well as potential future implications of devices as well as digital services on the environment. The 73rd DF LCA was opened with a welcome address given by René Itten (Zurich University of Applied Sciences, Switzerland). The program comprised five distinct sessions in order to tackle just as much different aspects of environmental impacts caused by digital transformation as well as relevant challenges for the LCA methodology:

- A first session was on digital transformation, introducing the concept of digital sobriety while highlighting potential risks and opportunities of increased digitization and provided a glimpse at the digital media use of young people in Switzerland (more details in Section 2).

- The second session addressed the resource use associated with digital transformation focusing on material and energy consumption as well as recycling of technology-critical elements in the context of a circularity (Section 3 ).

- The third session included a wide range of short presentations covering issues such as data centres as driver for industrial carbon reduction (Louise Mattson, RISE SICS North), the environmental assessment of cloud services in data centers (Ran Liu, Öko-Institut e.V.), the global energy footprint of IoT semiconductors (Sujit Das, Oak Ridge National Laboratory), synergies between blockchain technology and LCA (René Itten, Zurich University of Applied Sciences), electronics in the ecoinvent database (Lucia Valsasina, ecoinvent) and environmental implications of service life extension of mobile devices in the context of the ongoing project "Lifesaving" (Yann Blumer, Zurich University of Applied Sciences).

- The 1-day event was concluded in the afternoon with two sessions focusing on the challenges for the LCA methodology as well as the industrial perspectives from device manufacturers, addressing the inclusion of rebound 
effects, the multifunctionality of modern ICT devices and its inherent difficulties for LCA and the different LCA approaches applied by the device manufacturers (Sections 4 and 5).

- The discussion forum was framed with an online survey at the beginning and the end of the event that showed the participants' view on the effect of the digital transformation on the global environmental footprint (Section 6).

\section{Digital transformation and environment}

Hugues Ferreboeuf (the Shift Project, France) presented results from the Lean ICT report (Ferreboeuf et al., 2019) showing that the current trend of digital consumption (by buying and using products and services) in the world is unsustainable in terms of the supply of energy and materials that is required. Although technical progress has been driving high-energy efficiency gains, the digital carbon footprint is now increasing by about $8 \%$ a year because digital "volumes" (i.e. devices, network traffic, computing instances and stored data) are growing exponentially. As we are approaching the limits of current technologies and as there will be no technological breakthrough industrialised in the next 10 years, we'll need to make the digital ecosystem become more sober in order that digital energy consumption does not keep going up. This is mandatory if digitalisation should contribute positively to the goal of reducing by $50 \%$ the global GHG emissions in the next 10 years, which is itself a prerequisite to limit global warming to $2{ }^{\circ} \mathrm{C}$. The good news is that implementing this digital sobriety principle will still allow to pursue the ongoing digital transition, but it calls for a systemic approach targeting consumers, enterprises, vendors and regulators, which is what The Shift Project is currently focussing on.

Lorenz Hilty (University of Zurich, Switzerland) addressed opportunities and risks of the digital transformation stating that society is systematically missing the opportunities to develop sustainable patterns of production and consumption with the help of digital ICT. He supported this main thesis with arguments: (1) Digital technologies have become increasingly efficient in terms of energy and materials required, but higher demand for computing power, storage capacities, data transmitted and devices per person is systematically compensating for this progress (Aebischer \& Hilty, 2015; Hischier \& Wäger, 2015; Koomey et al., 2011), a trend which can be partially explained by rebound effects with regard to time, volume, weight and price. (2) Although data transmission can substitute or optimise physical transport with clear environmental benefits (Coroama et al., 2012; Hilty \& Bieser, 2017), physical transport is still growing. In particular, the airline industry expects that demand will double again within 20 years (IATA, 2018). The low prices for air transport do not reflect the scarcity of the global carbon budget. (3) Digitalisation can in principle increase the amount of functional units a physical asset delivers during its use phase, because software-controlled "smart" things can adapt to multiple users and changing requirements. With a growing fraction of objects becoming smart and part of the "Internet of Things", overall resource demand could decrease in theory. In practice, the opposite happens because software-controlled objects are also prone to software-induced obsolescence (Kern et al., 2018).

Regula Keller (Zurich University of Applied Sciences, Switzerland) presented results of the project "DigiSUFF" (Keller et al., 2019) showing the environmental impacts of digital media use of today's Swiss youth, aged between 12 and 25 years, assessed with the Swiss ecological scarcity method (Frischknecht \& Büsser Knöpfel, 2013). Included was the use of mobile phones, tablets, laptops, desktop computers and television devices as well as direct ownership and co-ownership of family-owned devices. Virtually, all young people (99\%) possess a mobile phone, and $30 \%$ possess a personal television. Mobile phones are used for $3 \mathrm{~h}$ per day and televisions for more than an hour. The analysis showed that a total of $78 \%$ of the impact is caused by the ownership of end user devices. Processing and provision of data in data centres is responsible for $15 \%$ of the impacts, which is negligible for most activities, except for watching television (13\%) and videos. The direct electricity demand of the end user devices is responsible for only few percents of the total impacts $(5 \%)$. Data transfer from the end user devices to the data centre and within the internet is of little relevance. From a consumer perspective, the highest reduction potential thus lies in the reduction of ownership of end user devices and the extension of their lifetime.

\section{Resource use of digitalisation}

Livia Cabernard (Swiss Federal Institute of Technology, Switzerland) presented results from the Swiss Minerals Observatory activities. They applied there a new method based on multi-regional input-output analysis in order to assess the impacts of global ICT manufacturing and to track them along the value chain with a focus on the impacts caused by the production of material resources used for ICT manufacturing (Cabernard et al., 2019). Their results show that between 1995 and 2015, climate change impacts of ICT manufacturing have doubled and the material footprint has quadrupled. In 2015, ICT manufacturing contributed $\sim 2 \%$ of global climate change impacts, whereby half is caused by the production of material resources used for ICT manufacturing. Efficient environmental policies should tackle materials like iron, steel, plastics and chemicals, which contribute half of the material-related impacts of ICT manufacturing. 
Switching to cleaner electricity production is essential, particularly in China, where $60 \%$ of the material-related climate change impacts of ICT manufacturing are caused. Improved supply chain management is crucial for other regions, which have increasingly outsourced their consumption-based impacts to China (e.g. EU, USA). The method used here is available as a tool and can be applied to extend the analysis, e.g. to further account for the use phase of ICT or localise users of ICT services.

Chris Preist (University of Bristol, UK) shared preliminary results comparing energy use and carbon footprint of television distribution over different technologies: traditional terrestrial broadcast, satellite, cable and streaming. He showed that traditional broadcast has the lowest footprint, while all three newer distribution technologies are roughly comparable. However, they have their hotspots in different places in the system. For cable and satellite distribution, the highfunctionality set-top boxes used are a significant hotspot, while for streaming it is the network equipment both within and outside the home. He argued that the energy and environmental impacts of a move to streaming may be to some extent mitigated by the elimination of the need for these highfunctionality set-top boxes in the home in the futurethough currently, households often have both. He pointed out the difference between the footprint of a traditional media provider such as the BBC and a new provider such as YouTube. These new providers encourage media consumption on the move, through the provision of short videos which can be engaged with quickly. As a result, they are accessed far more often over mobile services, and so, mobile network equipment is a significant hotspot (Preist et al., 2019). It has been commonly argued that the overall energy use and carbon footprint of digital technology globally is significant and roughly comparable in size to that of the aviation industry. However, Preist argued it is a far more 'egalitarian' technology than air travel. This means that each of our individual footprints is small, but many of us use the service: $58 \%$ of the world's population accessed the internet in 2019 (https:// www.internetworldstats.com/stats.htm). This means that individual behaviour change has little impact on one's personal carbon footprint, and it is important to design the digital services offered over the internet, and the infrastructure they run across, to be as efficient as possible.

Annemarie Falke (Technische Universität Bergakademie Freiberg, Germany) presented results of an ex-ante LCA study of indium recovery through bioleaching. The growing demand for mobile devices with displays caused among others by digitalisation will consequently lead to an increase of the electronic waste (e-waste) stream and a shortage of scarce resources such as indium. By dealing with the end-of-life products, e-waste-recycling offers a way towards reducing the pressure on such resources and towards a more circular economy, which aims at solutions for the whole product life cycle. By further assessing processes such as recycling of waste streams at an early stage in their technological development, hotspots can be identified, which allows finding ways to improve their environmental performance. LCA can be used as a tool for a sustainable development of such recovery processes. A lab-scale bioleaching process for the recycling of indium from liquid crystal display (LCD)-waste was assessed using ex-ante LCA, and a comparison with two existing chemical leaching processes was drawn. The studied bioleaching process is not yet competitive due to its early development stage. Results show that the electricity consumption due to high duration time and required comminution is the major contribution to environmental impacts. An ex-ante approach to LCA is possible and allows the determination of hot spots. However, assessments during the conceptual phase are prone to a high level of uncertainty and necessitate a high number of assumptions. (Falke \& Höck, 2019)

\section{Multifunctionality and rebound}

Jan Bieser (University of Zurich, Switzerland) shared insights on potential rebound effects of ICT, stating that ICT also has - in addition to the direct effects of producing, using and disposing ICT hardware - indirect effects on the environment. These latter effects are ICT-induced changes in patterns of consumption and production, also in domains other than ICT (e.g. e-commerce, car sharing, smart homes), and the environmental implications of these changes. ICT can have both, increasing and decreasing, effects on environmental loads, e.g. it can reduce transport through virtual mobility or increase transport by creating the desire to travel to places seen on the Internet (Bieser \& Hilty, 2018b; Hilty \& Bieser, 2017). Studies quantifying both, direct and indirect effects, often conclude that indirect effects are favourable (i.e. reducing $\mathrm{GHG}$ emissions) and clearly larger than direct effects. However, such studies often ignore systemic impacts of ICT use, e.g. ICT can stimulate transport demand; rebound effects, e.g. increase in demand due to efficiency increases, and ICTinduced behavioural changes (e.g. changes in shopping behaviour through e-commerce). The choice of assessment method and the approach to tackle such methodological challenges influences the results of these studies (Bieser \& Hilty, 2018c). In order to assess indirect environmental effects, a mixed-method approach (e.g. combining LCA with social science methods) is required (Bieser \& Hilty, 2018a).

Etienne Lees-Perasso (Bureau Veritas LCIE, France) presented the learning for LCA from the project "GreenConcept" (Sidos et al., 2020) focusing on multifunctionality and data availability. GreenConcept is an environmental assessment project aiming at providing life cycle-based environmental information on digital services to companies. Among the challenging aspects for the LCA of digital services are the multi- 
actor (multiple persons and companies are involved in a single digital service), multi-product (from the terminals, network and data centres, a lot of equipment is used) and multifunctionality (a single product can be involved in multiple functions). He stated that data availability is major hindrance for LCA, especially when including the use phase into the assessment. While LCI data for terminals are available, the knowledge on networks and data centres is currently rather limited and requires improvement. Regarding multifunctionality, he stated that allocation is a big challenge due to a wide variety of possibilities. He argued that that system expansion in order to avoid allocation is only valid for single-product LCA but impractical for a comparison of several products or services. Economic allocation would require information on the economic value of the different functionalities which are often difficult to determine, and physical allocation would require profound knowledge on the user behaviour. GreenConcept is succeeded by the project "Negaoctet"1 focusing on solving some aspects identified during the former project activities.

\section{Industry perspectives}

Jens Malmodin (Ericsson Research, Sweden) argued that although ICT and its use for Entertainment \& Media (E\&M) are growing fast, there are some major shifts in the use of devices since 2010 moving away from desktop PCs to laptops and smartphones, being much more efficient devices. He stated that the ICT and E\&M sector footprints grew very fast between 2005 and 2010 due to the growth of PCs but stabilised after a major shift in trend after 2010 due to a decrease in PC and TV sales. He argued that the move from E\&M to ICT also caused dematerialisation with smaller and more energyefficient mobile devices used in ICT reducing the increase in the global electricity demand for E\&M and ICT. He also argued that the ICT sector's electricity consumption remained rather stable after 2010, and the associated greenhouse gas emissions even slightly decreased due to the transformation towards more renewable electricity. With an increased use of renewable electricity, this could be even further reduced down to half the greenhouse gas emissions in 2030 compared with 2020. Furthermore, he stated that the rate of data traffic increase per 5 years drastically reduced from an increase in data traffic of 70 times between 1995 and 2000 to about 3 times between 2010 and 2015 and highlighted that more data does not directly translate into more energy and greenhouse gas emissions. He concluded with the statement that ICT can also help society to reduced greenhouse gas emissions and that we need to find better ways for ICT to help us in these efforts.

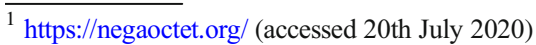

Anders S.G. Andrae (Huawei Technologies, Sweden) presented an expose of six quick LCA methods applied to a smartphone including the (1) advanced eco-rating LCA (AERLCA), (2) the remaining value (RV) input-output (IO) correction and (3) Carbon Disclosure Project (CDP) normalization methods. The main characteristics and metrics used for each were listed. RV IO provided the highest-but still reasonable - absolute Product Carbon Footprint (PCF) score and share of the upstream. All methods showed that screens, integrated circuits (ICs) and printed circuit boards (PCBs) dominate the production PCF. However, the specific contributors to the RV IO based upstream $\mathrm{CO}_{2}$-eq score are unknown. AERLCA is the most flexible and complete including losses in PCB and aluminium part production and full end-oflifetime modelling. CDPLCA shows a big contribution from Screens, AERLCA from PCBs. Although this is confusing, the AERLCA is overall the most sensible in a wider ICT goods context. CDPLCA can give quick access to primary/ specific carbon per money intensities to be used in PCF of specific designs. Andrae argued that the new trends of application programming interfaces in LCA software - and the use of blockchain in life cycle inventory data collection-imply that LCA can indeed be used for eco-design of ICT supply chains.

\section{Discussions and conclusions}

All the presentations and their discussion during the day showed the high environmental relevance of the global digital transformation. Emphasized were in particular environmental impacts caused by the manufacturing of electronic devices and their components in Asia including their demand for various raw materials as well as the energy demand for operating the global internet infrastructure. The discussions also revealed that devices and hardware are dominating the environmental impacts for the end users since the computational power highly exceeds their actual requirements. This is amplified by a still continuously growing number of different devices possessed by a single end user. However, this only applies for end users. In the case of cloud service providers whose servers are operated at almost full capacity, the energy consumption of the servers during use phase is by far the most relevant factor.

The discussion on the current trends of digitalisation and their ecological implications was however rather controversial. While there was a consensus that digital volumes are expected to increase in the upcoming years, the ecological impacts of this increase were heavily discussed. Regarding the future developments, the discussion revealed a wide variety of potential factors that could drastically increase the data volume and traffic and have manifold, potential rebounds, such as a heavy increase in surveillance and streaming 
Fig. 1 Participants' view on the effect of the digital transformation on the global environmental footprint
How will digital transformation change our environmental footprint?

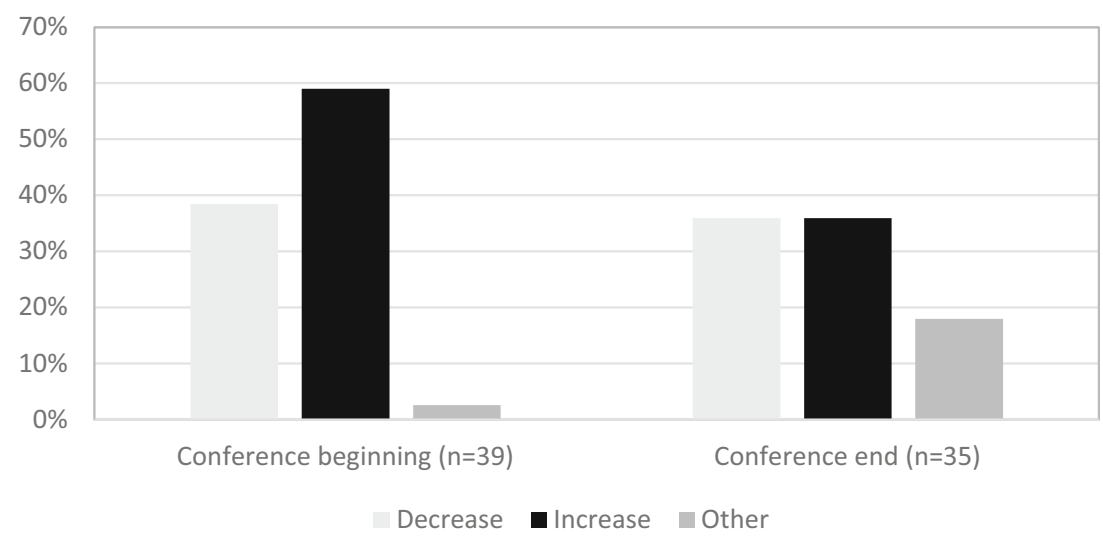

services. Of importance when assessing the potential impacts is the general accessibility of digital technologies with around $60 \%$ of the world population having access to the internet causing only small effects to have a high impact on a global scale. However, consensus was that these developments are still evolving and can be heavily influenced by an appropriate legal framework.

Furthermore, the speakers agreed on a lack of sufficient highquality inventory data along the life cycle of networks and data centres and to a lesser extent for electronic devices. Since many LCA projects in ICT currently rely on inventory data that are outdated, highly uncertain or simply not available, there is a need for more transparent, up-to-date inventory data on manufacturing, operating and disposing ICT-related devices.

In general, the forum leads to an engaged discussion revealing various options for potential implications and only little consensus on their actual impacts, which was confirmed by the online survey before and after the forum. During the welcome session at the beginning as well as during the wrap-up at the conference end, the participants were asked to take part in a live online survey where they could express their view on how the digital transformation affects the global environmental footprint. In the morning and afternoon, 39 and 35 people engaged in the survey, respectively (see Fig. 1). At the beginning of the conference, a majority of $59 \%$ expressed their view that the digital transformation leads to a higher environmental footprint. Only a minority of $38 \%$ supported the assumption that the digital transformation leads to a decrease in environmental footprint. However, during the conference day, this picture changed, and at the end of the discussion forum, both views had an equal number of supporters with $36 \%$ each (see Fig. 1).

The online survey moderated by Matthias Stucki (Zurich University of Applied Sciences) showed a reduction of participants who considered ICT as a source for a higher global environmental footprint. This change could be explained by the presentation of Lorenz Hilty who showed opportunities of digitalization to - at least in principle - significantly reduce emissions by substituting more environmentally intensive services such as air travel and the presentation of Jens Malmodin who showed that the shift to renewable energy, increased energy efficiency and smaller devices led to a smaller environmental footprint.

LCA can support the pathway to a more environmentally sustainable digital transformation by pointing out environmental hotspots of ICT, by identifying environmental tradeoffs, by monitoring the environmental impacts of the digital transformation and by showing the sustainability potentials of substituting digital for non-digital technologies with high environmental impacts.

Acknowledgements This publication is based on research supported by the Swiss National Science Foundation (SNSF) within the framework of the National Research Programme "Sustainable Economy: resourcefriendly, future-oriented, innovative" (NRP 73) Grant-N 407340 185630 .

Open Access This article is licensed under a Creative Commons Attribution 4.0 International License, which permits use, sharing, adaptation, distribution and reproduction in any medium or format, as long as you give appropriate credit to the original author(s) and the source, provide a link to the Creative Commons licence, and indicate if changes were made. The images or other third party material in this article are included in the article's Creative Commons licence, unless indicated otherwise in a credit line to the material. If material is not included in the article's Creative Commons licence and your intended use is not permitted by statutory regulation or exceeds the permitted use, you will need to obtain permission directly from the copyright holder. To view a copy of this licence, visit http://creativecommons.org/licenses/by/4.0/.

\section{References}

Aebischer B, Hilty LM (2015). The energy demand of ICT: a historical perspective and current methodological challenges

Belkhir L, Elmeligi A (2018) Assessing ICT global emissions footprint: trends to 2040 \& recommendations. J Clean Prod 177:448-463 
Bieser J, Hilty L (2018a). An approach to assess indirect environmental effects of digitalization based on a time-use perspective. In Proceedings of EnviroInfo 2018. Munich, Germany.

Bieser J, Hilty L (2018b) Assessing indirect environmental effects of information and communication technology (ICT): a systematic literature review. Sustainability 10(8):2662

Bieser J, Hilty L (2018c). Indirect effects of the digital transformation on environmental sustainability methodological challenges in assessing the greenhouse gas abatement potential of ICT. In B. Penzenstadler, S. Easterbrook, C. Venters \& S. I. Ahmed (Hrsg.), ICT4S2018. 5th International Conference on Information and Communication Technology for Sustainability (Bd. 52, S. 14). Toronto, Canada: EasyChair

Cabernard L, Pfister S, Hellweg S (2019) A new method for analyzing sustainability performance of global supply chains and its application to material resources. Sci Total Environ 684:164-177

Coroama VC, Hilty LM, Birtel M (2012) Effects of internet-based multiple-site conferences on greenhouse gas emissions. Telematics Inform 29(4):362-374

Falke A, Höck M (2019) Ex-ante life cycle assessment of bioleaching in indium recovery from LCD-waste. MRS Advances 4(35):19491955

Ferreboeuf H, Efoui-Hess M, Kahraman Z (2019) Lean ICT - towards digital sobriety. The Shift Project, Paris, France

Frischknecht R, Büsser Knöpfel S (2013). Swiss Eco-Factors 2013 according to the Ecological Scarcity Method. Methodological fundamentals and their application in Switzerland (S. 254-254). Berne: Federal Office for the Environment

Hilty L, Bieser J (2017) Opportunities and risks of digitalization for climate protection in Switzerland. University of Zurich, Zurich
Hischier R, Wäger PA (2015). The transition from desktop computers to tablets: a model for increasing resource efficiency? In Hilty, L.M., Aebischer, B. (eds.) ICT Innovations for Sustainability. Advances in Intelligent Systems and Computing (Bd. 310, S. 243-256). Springer, Switzerland

IATA. (2018). IATA forecast predicts 8.2 Billion Air Travelers in 2037

Keller R, Stucki M, Itten R (2019) Projekt Digitale Suffizienz Ökobilanzbericht zur Nutzung digitaler Geräte durch Jugendliche in der Schweiz. Institut für Umwelt und Natürliche Ressourcen ZHAW, Wädenswil

Kern E, Hilty LM, Guldner A, Maksimov YV, Filler A, Gröger J, Naumann S (2018) Sustainable software products - towards assessment criteria for resource and energy efficiency. Futur Gener Comput Syst 86:199-210

Koomey J, Berard S, Sanchez M, Wong H (2011) Implications of historical trends in the electrical efficiency of computing. IEEE Ann Hist Comput 33(3):46-54

Preist C, Schien D, Shabajee P (2019) Evaluating sustainable interaction design of digital services: the case of YouTube. In: Proceedings of the 2019 CHI conference on human factors in computing systems. Association for Computing Machinery, Glasgow, pp 1-12

Sidos M, Fernique C, Fraisse T, Amphoux A, Vateau C, Bordage F, Prunel D, Domon F (2020) GreenConcept action white paper (Livre Blanc de 1'action GreenConcept). Greenconcept écoconception numérique, Blagnac, France

Publisher's note Springer Nature remains neutral with regard to jurisdictional claims in published maps and institutional affiliations. 